\title{
Manubriosternal arthrodesis: A novel surgical approach for refractory osteoarthritis
}

\author{
Thomas A. Mitchell, MD, ${ }^{\mathrm{a}}$ Joseph F. Alderete, MD, ${ }^{\mathrm{b}}$ and Bryan S. Helsel, MD, ${ }^{\mathrm{c}}$ San Antonio, Tex
}

Osteoarthritis of the manubriosternal joint (MSJ) is generally treated with medical therapy, including antiinflammatory medications and intra-articular steroid injections; however, surgical intervention may be needed. We describe a novel operative intervention in a patient with primary MSJ osteoarthritis. Oral consent was obtained from the patient before publication.

\section{CLINICAL SUMMARY}

A 41-year-old man was referred to the cardiothoracic surgery outpatient clinic for evaluation of an atypical chest pain after completion of multiple tests with nondiagnostic results: electrocardiogram, chest radiography, and chest computed tomography. The patient reported 11 months' duration of a nonradiating discomfort present directly over the MSJ with some intermittent exertional dyspnea. The patient had no trauma to his chest wall. Exacerbating factors included push-ups, pull-ups, and other daily military activities; importantly, the discomfort was affecting his sleep patterns. Medical history was significant for hypertension, posttraumatic stress disorder, and a previous knee surgery. Current medications included lisinopril, Elavil (AstraZeneca, Wilmington, Del), prazosin, and Flexeril (Ortho-McNeil-Janssen Pharmaceuticals, Titusville, NJ); specifically, Tylenol (McNeil Consumer Healthcare, Fort Washington, Pa), Motrin (McNeil Consumer Healthcare), and Flexeril had failed to alleviate his primary MSJ osteoarthritis. Family history was noncontributory, with an allergy to sulfa that precipitated systemic swelling. Social history was significant for an 18 pack-year smoking history. Physical examination demonstrated reproducible discomfort on compression of his MSJ. Laboratory revealed a creatinine of $1.29 \mathrm{mg} / \mathrm{dL}$. Preoperative noncontrast chest

\footnotetext{
From the Departments of General Surgery, ${ }^{\mathrm{a}}$ Orthopedic Surgery, ${ }^{\mathrm{b}}$ and Cardiothoracic Surgery, ${ }^{\mathrm{c}}$ San Antonio Military Medical Center, San Antonio, Tex.

Disclosures: Authors have nothing to disclose with regard to commercial support.

The opinions or assertions contained herein are the private views of the authors and are not to be construed as official or as reflecting the views of the Department of the Army or the Department of Defense.

Received for publication Jan 30, 2014; revisions received March 18, 2014; accepted for publication July 12, 2014; available ahead of print Aug 26, 2014.

Address for reprints: CPT Thomas A. Mitchell, MD, Department of General Surgery, San Antonio Military Medical Center, 3551 Roger Brooke Dr, Fort Sam Houston, San Antonio, TX 78234 (E-mail: thomas.a.mitchell.mil@mail.mil).

J Thorac Cardiovasc Surg 2014;148:e232-3 0022-5223/\$0.00

Published by Elsevier Inc. on behalf of The American Association for Thoracic Surgery

http://dx.doi.org/10.1016/j.jtcvs.2014.07.036
}

computed tomography demonstrated MSJ arthrosis and a subchondral cyst, with a safe bicortical screw and drill stop length. Electrocardiography demonstrated a normal sinus rhythm with nonspecific T-wave changes. Preoperative risk counseling for surgical MSJ arthrodesis with autologous bone graft included discussion of the risks of damage to surrounding structures, loss of motion, chronic pain, need for further surgical intervention, and failure to achieve the goal of the surgery.

\section{Operation}

With the patient in a supine position, the thoracic cavity and bilateral lower extremities were prepared and draped. A 6-cm vertical incision was centered over the MSJ, with subsequent division of the pectoralis fascia to create periosteal flaps circumferentially to expose the angle of Louis, MSJ, manubriocostal joint, and sternocostal joint. The patient's MSJ was resected, including a subchondral cyst present on the right portion of the MSJ, with a 5-mm high-speed bur. Next, a Synthes winged H plate (Synthes, Inc, West Chester, $\mathrm{Pa}$ ) was inserted to fuse the residual sternum and manubrium together with two 14-mm depth screws. Bicortical screws were then used to attach the Synthes winged $\mathrm{H}$ plate to the first rib bilaterally. Autologous bone graft harvested from the patient's left tibia was then interspersed around the Synthes winged $\mathrm{H}$ compression locking plate (CLP), which is depicted in Figure 1. The patient was transferred to a step-down unit for postoperatively telemetry monitoring.

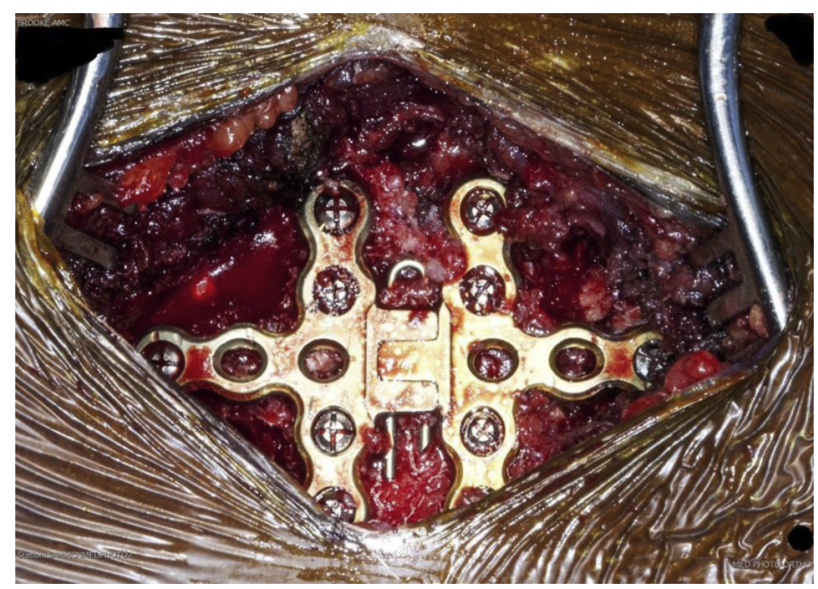

FIGURE 1. Intraoperative photograph of manubriosternal joint immobilization with autologous bone graft from the left tibia. 




FIGURE 2. Chest computed tomography at 4 postoperative months.

\section{Postoperative Follow-up}

No adverse events occurred postoperatively, and the patient was discharged home on postoperative day 4 . Currently, he is participating in outpatient physical therapy to facilitate his recovery. His 4-month postoperative chest computed tomography is shown in Figure 2.

\section{DISCUSSION}

Osteoarthritis is a degenerative joint disease with pathognomonic findings of erosion of the articular cartilage, hypertrophy of bone margins, and subchondral sclerosis. ${ }^{1}$ In industrialized societies, osteoarthritis is the leading cause of impaired quality of life; however, the incidence of symptomatic osteoarthritis of the MSJ is unknown. The MSJ, a secondary cartilaginous joint (symphysis), may resemble a synovial joint susceptible to osteoarthritis degeneration, because $30 \%$ of patients may undergo fibrocartilage disk absorption. ${ }^{2}$ Primary MSJ osteoarthritis has no identifiable etiology; secondary osteoarthritis results from rheumatoid arthritis, psoriatic arthritis, ankylosing spondylitis, or gout.
Medical therapy is the first-line therapy for MSJ arthritis, including anti-inflammatory medications and intra-articular steroid injections; however, patients with significant impairment in quality of life despite maximal medical therapy need viable treatment alternatives. ${ }^{3}$ Several case reports have described MSJ arthrodesis or arthroplasty for primary and secondary osteoarthritis unrelated to trauma. In addition to débridement of the MSJ, Shewring and Carvell ${ }^{4}$ have described autologous transplantation of iliac crest bone graft for secondary osteoarthritis from gout. Al-Dahiri and Pallaster ${ }^{2}$ performed MSJ arthrodesis with autologous bone graft from the hypertrophic portion of the MSJ for primary osteoarthritis, comparable to the use of an autologous bone graft from the left tibia in our patient. Specifically, resection of the MSJ, CLP stabilization of the MSJ with lateral stabilization to the ribs, and the use of autologous bone graft interspersed within the CLP facilitates future MSJ immobilization to alleviate symptoms from primary MSJ osteoarthritis.

Although the final surgical outcome is pending further rehabilitation, this novel operative intervention for primary MSJ osteoarthritis may be indicated for patients whose quality of life is significantly negatively impacted despite maximal medical therapy. Ultimately, the possible benefits of this operation to improve primary osteoarthritis discomfort and overall quality of life must be juxtaposed with the risks of surgical complications, medical costs (including nearly $\$ 2000$ for the CLP and screws), operative and recovery times, and the potential failure of symptom relief. Surgeons must individually tailor this novel therapy to each patient during preoperative counseling.

\section{References}

1. Di Cesare PE, Haudenschild DR, Samuels J, Abramson SB. Pathogenesis of osteoarthritis. In: Firestein GS, Budd RC, Gabriel SE, McInnes JB, O'Dell JR, eds. Kelley's textbook of rheumatology. 9th ed. Philadelphia: Elsevier Saunders; 2013:1617-35.

2. Al-Dahiri A, Pallister I. Arthrodesis for osteoarthritis of the manubriosternal joint Eur J Cardiothoracic Surg. 2006;29:119-21.

3. Fournié B, Boutes A, Dromer C, Sixou L, Le Guennec P, Granel J, et al. Prospective study of the anterior chest wall involvement in ankylosing spondylitis and psoriatic arthritis. Rev Rhum Engl Ed. 1997;64:22-5.

4. Shewring DJ, Carvell JE. Arthrodesis for recurrent manubriosternal gout. J Bone Joint Surg Br. 1991;73:341. 